\title{
The Effects of Mobbing in the Workplace on Service Innovation Performance: The Mediating Role of Boreout
}

\author{
Fahri ÖZSUNGUR iD) a \\ a Adana Alparslan Türkeş Science and Technology University, Adana, Turkey. ozsungur@adanato.org.tr
}

\begin{tabular}{|c|c|}
\hline ARTICLE INFO & ABSTRACT \\
\hline Keywords: & $\begin{array}{l}\text { Purpose - The study aims to explore the mediating role of boreout by revealing the effects of } \\
\text { mobbing and their effects on service innovation performance employees in the retail industry. }\end{array}$ \\
\hline $\begin{array}{l}\text { Mobbing } \\
\text { Service innovation performance } \\
\text { Retail industry }\end{array}$ & $\begin{array}{l}\text { Design/methodology/approach - This study was conducted with } 209 \text { participants recruited from } \\
\text { retail companies registered to Adana Chamber of Commerce in the province of Adana Turkey in } \\
\text { October 2019. The research was analyzed by the SEM method based on the social exchange theory. }\end{array}$ \\
\hline $\begin{array}{l}\text { Received } 24 \text { November } 2019 \\
\text { Revised } 22 \text { January } 2020 \\
\text { Accepted } 7 \text { February } 2020\end{array}$ & $\begin{array}{l}\text { Findings - Findings revealed that boreout and mobbing were negatively associated with service } \\
\text { innovation performance and mobbing was positively associated with boreout. According to } \\
\text { another finding, boreout partially mediated the effect of the mobbing on service innovation } \\
\text { performance. }\end{array}$ \\
\hline $\begin{array}{l}\text { Article Classification: } \\
\text { Research Article }\end{array}$ & $\begin{array}{l}\text { Discussion - The study reveals the boreout, mobbing status of the employees serving in the retail } \\
\text { industry and service innovation performance of the retail companies. Limitations of the study, } \\
\text { discussions and suggestions were included in the study. }\end{array}$ \\
\hline
\end{tabular}

\section{Introduction}

The workplace is an important part of life where employees spend an important part of their lives with their colleagues and superior. Employees have crucial relations with people and they affect the customers' economic, social and legal status regarding the service they offer. This interaction creates an unlike sense of employees at work. It is not a rational approach to limit the service behavior of human beings with external factors who have a cognitive dissonance with their inner world (Hastie and Pennington, 1995). Individuals are extremely sensitive to the external environment and are under cathexis (Laplanche and Pontalis, 2006). The cathexis is comprised of a process including the effect on the individual coupled with the external environment, transmutation of emotional conflict in the cognitive process, releasing energy, and developing behavior (Erwin, 2002). This process reveals individual attitudes and biases. This interaction and processes take place a crucial role in the workplace. Employees feel positive or negative feelings in their relations with their colleagues, superiors, and customers. The internal climate of the workplace may affect employee behavior and sense. Coworker or customer relations with employees reveal affective meaning and pressure in this workplace climate. Negative psychological state is one of an output of affective interaction. This effect can be caused by psychological state, individual, psychological, environmental and familial problems, and problems with colleagues. One of these negative conditions is bore-out. This syndrome occurs in the form of job boredom, crisis of meaning, and crisis of growth and is a negative psychological status of employees (Stock, 2015). This psychological effect is related to the perception of meaninglessness about the job of the employee and the individual feeling unhappy in his/her job. The individual has the perception that the job does not provide an opportunity to develop itself in the work-related interaction. This may hamper the productivity and innovative behaviors of the employee.

The most powerful traumatic problem in the workplace is mobbing. Mobbing is one of the most difficult cases to prove in today's business world. The fact that the events occurring in the workplace are under threat of dismissal, the weakness of the economic situation of the individual and the increasing need for work is increasing day by day reveal the mobbing as a reality. The fact that the laws varying from country to country is against the employee makes mobbing even stronger. Mobbing is often seen in the business world of

\section{Önerilen Atıf/ Suggested Citation}

Özsungur, F. (2020). The Effects of Mobbing in the Workplace on Service Innovation Performance: The Mediating Role of Boreout, Journal of Business Research-Turk, 12 (1), 28-42. 


\section{F. Özsungur 12/1 (2020) 28-42}

developing countries. Employees have to work on one hand under this psychological pressure and on the other hand, they are under the burden of supporting their family. This dilemma causes the individual to experience psychological problems, to have conflicts with co-workers in the workplace and to question the value and meaning given to work. In this conflict and chaos environment, the individual experiences a conflict of identity within itself. In this case, the individual may not be able to perform positive behaviors such as contributing to the organization and making innovative actions. For this reason, the effects of mobbing on service innovation performance, which is closely related to the business world and economy with its social and individual dimensions, are examined in the context of boreout. The study aims to determine the mediating role of boreout by revealing the effects of mobbing of the employees who play an important role in the performance of organizations, and their effects on service innovation performance.

\section{Mobbing}

Mobbing has been the subject of research for many years, but it has not been found a practical solution. This action emerged with the first master-slave relationship and evolved along with the industrial revolution. Developing technology and changing needs have also changed the manner and effect of mobbing. This change caused various definitions of mobbing. Leymann (1996) expressed mobbing as hostile behaviors and harassment in organizations. Vega and Comer (2005) described mobbing as actions that cause psychological stress and environmental losses, and reduce productivity. Mobbing is an oppressive, insulting, threatening behavior by the supervisors and co-workers that negatively affects employees from a psychological (Agervold and Mikkelsen, 2004), physical, social and economic points of view (Zapf and Einarsen, 2001). These behaviors may be carried out by the supervisor or by employees who have not been adopted him/herself by their colleagues in the workplace. Mobbing is the intentional act actualized in the workplace. Supervisor's deliberately ignoring discrimination, harassment and oppression by her/his colleagues is a mobbing. Therefore, two types of basic mobbing can be carried out in the conduct of mobbing by the supervisor: passive/indirect and active/direct. In an "active mobbing", supervisor or co-workers show the employee that they don't want her/him in the workplace with their behaviors. Active/direct mobbing is that the employee is exposed to behaviors such as harassment, psychological pressure, threat, intimidation, insult, heavy workload by supervisor or co-workers. Passive/indirect mobbing is the act of deliberately ignoring the employee, allowing the harassment and oppressive behaviors of other employees. Employees are tried to be fatigued in terms of psychological, social, economic and physical aspects. This exhaustion is carried out for the employees to withdraw their position/task or job and to comply with the orders of the supervisor.

There are few studies in the literature with mobbing. Serin, Balkan and Doğan (2014) found that there was a positive association between causes of mobbing and personal dignity. Garthus-Niegel et al. (2015) revealed mobbing as a risk factor for health-related outcomes. Mardanov and Cherry (2018) revealed that coworker bullying had stronger associations with negative acts than abusive supervision, mobbing caused unfavorable workplace incidents, coworker bullying and group mobbing negatively affected the victim's well-being. Studies showed that negative acts have effects on victimization via mobbing (Mardanov and Cherry, 2018; Zapf and Einarsen, 2005; Zapf, Knors and Kulla, 1996).

H1.Mobbing is negatively associated with service innovation performance.

\section{H2. Mobbing is positively associated with boreout.}

\section{Service Innovation Performance}

Service innovation performance takes place with employee service innovation behavior and the development of new services (Hu et al., 2009). Measuring the performance of an enterprise as a result of innovative behaviors depends on the creation of new services or products developed with human-based behaviors. The measurement of the performance of the enterprise for innovation is important for its success in entrepreneurship. To gain a competitive advantage by evaluating the opportunities, innovation performance needs to be improved (Woodruff, 1997; Kandampully and Duddy, 1999). To remain dynamic by adapting to the environment of an enterprise and to avoid rigor mortis the product or service provided should be given the utmost importance. Otherwise, the company is present in a palliative disease that cannot go beyond providing existing products and services. The treatment of this disease is innovation. Regardless of the type of industry, service is important for customers. To realize innovation in the service offered to customers, 


\section{F. Özsungur 12/1 (2020) 28-42}

attitudes towards product or service should be determined in carrying out buying behaviors. How a quality product is delivered to the customer, for example, providing a quality service to the customers of a bus company operating in the production sector shows the importance of service innovation for the customer (Garg and Dhar, 2017). Nowadays, the quality of the products, the emphasis of customers' presentation and offering services is increasing. For this reason, service innovation is a crucial indicator of quality for customers and enterprises.

Service innovation is the level of development of new services, techniques and methods of the enterprises as a result of employees' creative and innovative ideas (Kindström et al., 2013; Chen, 2011). Service innovation performance is the level of providing the resources, environment, process and human resources required to develop new services, techniques and methods that the enterprise displays together with its employees (Barcet, 2010; Carlborg, Kindström, and Kowalkowski, 2014). The service innovation behavior is the combination of employees seeking new services, techniques, and methods, preparing the processes, maintenance of the resources, producing innovative and creative ideas, the dissemination and implications in the workplace. Service innovation takes place with the common actions of employees and enterprises. Service innovation performance is the output of these two actions. This output can be achieved by operating profitability, sustainable competitive advantage, entering new marketing, new service development, and growth (Dess and Picken, 2000).

Service innovation occurs or develops as a result of communication with people (Berthon and John, 2006). Psychological, social and economic states affecting individual perception and behaviors are effective in this interaction. Santamarı'a, Nieto, and Miles (2012) found that close cooperation with customers is positively associated with service innovation. In a study conducted by Schmit and Allscheid (1995) using the attitude, intention, behaviors model of Bagozzi (1992), it is revealed that the assessment of the service climate by the employee affected intentions and behaviors. Hussain, Konar, and Ali (2016) found that team culture and knowledge sharing positively assiciated with service innovation performance. When these studies are evaluated together, it is thought that the negative psychological status of the employee related to her/his job would affect the service innovation behavior of the individual and the performance of the organization in this aspect.

\section{Bore-out syndrome}

Bore-out is a negative psychological state of low work-related spirituality, includes three main forms: a crisis of meaning at work, crisis of growth, and job boredom. This syndrome is that the job of the individual in the workplace becomes meaningless, the job does not mean anything to her/him, she/he is upset about meaningless and gets bored of her/his job. These feelings cause the individual not to focus on his / her work. The main reason for this is that the job does not offer opportunities for personal development for the individual and that the job does not teach new things to the individual. Bore-out is an important stress factor in the workplace in light of this knowledge. This stress factor can be caused by actions such as mobbing, ignoring, or lack of task assignment. These actions cause the individual to be bored, disappointed and unable to focus on his job (Stock, 2015).

\section{H3. Boreout is negatively associated with service innovation performance.}

The meaninglessness of the work can occur in various ways. An individual who has been harassed, constantly having problems with his colleagues, constantly discredited by his manager, being devalued by his worth, and undermined by insignificant tasks in the workplace may face this negative psychological state. Boreout is derived from the personal identity theory (Dutton, Roberts and Bednar, 2010). The main idea of this theory is related to "person" and "self. The individual can make an important distinction between being a social being and being himself in a social environment. Expectations and perceptions lead to the emergence of individual identity. "Person" occurs when an employee compares himself to her/his colleagues in the workplace. When the employee focuses on his / her characteristics, in case "self" occurs. Problems with this dilemma may cause bore-out syndrome. The main theory on which this syndrome is based on the social exchange theory (Blau, 1964). Social life renews itself through interpersonal interaction. The business world is an important interaction tool in social life. The interaction between the employee and the organization takes place through mutual interest expectation and balance. While the employee expects material or spiritual output for his / her service, the employer and the organization expects service and production for the continuity and profitability of the 


\section{F. Özsungur 12/1 (2020) 28-42}

business. The deterioration in the balance of justice as a result of this interaction may cause boreout syndrome. Job boredom, crisis of meaning at work, and crisis of growth are not self-evident situations (Stock, 2015). These three situations arise with the experiences of the individual in the workplace. Individual perceptions and thoughts are important tools in providing this output. Stock (2015) stated that the crisis of growth and the crisis of meaning at work and negatively associated with employee innovative work behavior contrary to job boredom. Moeller et al (2018) found a negative inter-individual correlation between engagement and burnout. According to Stock (2016) crisis of meaning at work, job boredom and the crisis of growth which were the dimensions of boreout negatively effected customer-oriented behavior. These studies show that employees are significantly affected by negative attitudes and behaviors in the workplace. However, these studies do not disclose the effects of boreout on mobbing in terms of employee and innovation in terms of organization. There are no studies in this direction in the literature, only a few studies have been found about boreout.

H4. Boreout mediates the association between mobbing and service innovation performance.

\section{Methods}

\subsection{Participant}

The universe of the study was determined as employees working in the retail sector in Adana. Accordingly, based on information received from Adana Chamber of Commerce in Turkey as of 2019 the number of employees in this sector, 1,000,826, and 19,052 in Adana. The error level of the selected sample is 5\% at a $90 \%$ reliability level (Özdamar, 2003). Participants $(\mathrm{N}=209)$ were recruited from retail companies registered to Adana Chamber of Commerce in the province of Adana Turkey in October 2019. Participants were selected according to the following criteria: a) working in the retail industry b) providing service. Adana Chamber of Commerce and participants (business executives) approved this study procedures. The study was conducted with four interviewers in Turkish. The companies that have a service department for their customers were selected randomly. The reason why the companies operating in the retail industry are selected for the research is to determine boreout, mobbing and service innovation performance in the retail industry. The reason for the selection of Adana province of Turkey in terms of taking place between the provinces in the emerging industry and having a coast on the Mediterranean. Participants were informed clearly that they were willing to participate in the survey and that they could end the process at every stage of the survey. Therefore, no study was conducted with participants who did not want to participate in the survey.

\subsection{Measures}

Boreout (BRT) was assessed using 11 items and three subscales developed by Stock (2015). This study was fulfilled by 142 frontline employees. Four items measured the "crisis of meaning at work" (CMW) inspired by Schnell (2010). This subscale determined the perception of emptiness, meaningless senses pertain to work. Three items measured job boredom (JB) developed by Fisher (1998). This dimension measured the displeasure state arising from low work-related stimuli. Four items measured the crisis of growth (CG) inspired by Bakker et al. (2010). This subscale determined the belief that job provided personal development, achievement, learning, and independent thought opportunities. The BRT scale measured the state of meaningless, bored and frustrated sense of work. Participants responded to these items on a seven-point Likert-type scale, where $1=$ strongly disagree and $7=$ strongly agree " as anchors were employed. CMW and JB scores were calculated as $1=$ strongly disagree and $7=$ strongly agree. On the contrary, CG was calculated as $1=$ "strongly agree" and 7 = "strongly disagree". For BRT, scoring of the scale changes as 1 to 7 .

Items on the Service innovation performance (SIP) scale were obtained from Hu, Horng, and Sun (2009). The scale consists of 14 items. The scale consists of two sub-dimensions: Employee service innovation behavior (ESIB) (6 items), Development of new services (NSD) (8 items). ESIB items are adapted from Scott and Bruce (1994) and NSD items are adapted from Matear et al. (2004). ESIB includes the state of innovativeness and creativeness. NSD measures the readiness state of the business and the service team with new services. The scale was measured using a 6-point Likert-type scale ( 6 ="strongly agree"; $1=$ "strongly disagree").

The workplace mobbing was measured using a 5-item scale labeled Luxembourg Workplace Mobbing Scale (WM) developed by Steffgen et al. (2016). Four items were developed from the Leymann Inventory of Psychological Terror (Leymann, 1996). The questionnaire was comprised of a 5-point-Likert scale. Scoring of the scale changes as 1 (= Never) to 5 (= Almost at all times). Scores on the WM were calculated as reflecting a 


\section{F. Özsungur 12/1 (2020) 28-42}

higher level of mobbing status. The Cronbach's alpha value of the scale for the total sample was $\alpha=.73$ (German version), for the Luxembourgish version was $\alpha=.76$, for the French version was $\alpha=.71$.

\section{Procedure}

\section{Data analysis}

Confirmatory factor analysis was performed using AMOS software to measure the validity and reliability of the measurement tools (Hu and Bentler, 1999; Gefen, Straub and Boudreau, 2000). The model fit values are determined by calculating the criteria for $\chi 2, \chi 2 / \mathrm{df}$, RMSEA, SRMR, GFI, AGFI, CFI, IFI, NNFI (TLI). $\chi 2$ (ChiSquare) measures the magnitude of discrepancies between sample and covariance matrices. However, when the sample size is high, it can produce meaningless results when low and the number of variables increases. Instead of covariance linking the errors of variables can cause meaningless values (Maruyama, 1998; Tanaka, 1993). Root Mean Square of Error Approximation (RMSEA), is used to determine how well the populations with unknown and optimally selected parameter estimates fit into the covariance matrix.

The RMSEA depends on the sensitivity of the estimated number of parameters (Byrne, 1998). Standardized Root Mean Square Residual (SRMR) is the square root of the difference between the sample covariance matrix and the residual values of the hypothesized covariance model. SRMR is used to determine the problems arising from the indicators of the measurement tools in the research. If the indicators differ (e.g. 7-point Likert in some of the scales and 5-point Likert in others), it becomes difficult to interpret the RMR (Root Mean Square Residual). The SRMR is used to measure whether the model fits well (Kline, 2005, 2016). GFI (Goodness of Fit Index) which is developed as an alternative to the Chi-Square test, calculates the variance ratio calculated with the estimated population covariance (Tabachnick and Fidell, 2007). It was observed that this value increased in large samples and the number of parameters increased (Miles and Shevlin, 2007; MacCallum and Hong, 1997; MacCallum, Browne and Sugawara, 1996).

AGFI (Adjusted Goodness of Fit) adjusts the GFI according to degrees of freedom and tends to increase with the sample size. It is recommended not to use these values because of their degree of freedom and their sensitivity depends on the sample size (Sharma, Mukherjee, Kumar and Dillon, 2005). IFI (Incremental Fit Index) is a comparative or relative index that is insensitive to the sample size. To determine the IFI, the variance between the Chi-Square of the independent model in which the variables do not correlate and the Chi-Square of the target model must be calculated. Then, the difference between the chi-square and the " $\mathrm{df}^{\prime \prime}$ value of the target model must be calculated. The ratio of these values indicates IFI (Bollen, 1989). NNFI (Non-Normed Fit Index) alias the TLI (Tucker-Lewis Index) is a gradual model fit indices. In small samples, it may indicate low fit despite other fit indices. However, although some of the other fit indices that are sensitive to sample size are low, the NNFI value may be acceptable or good fit (Bentler, 1990; Kline, 2005; Tabachnick and Fidell, 2007). 


\section{Results}

\section{Demographics}

Demographic variables were presented in Table 1.

Table 1. Personal demographic variables table

\begin{tabular}{llll}
\hline Demographics & & f & \% \\
\hline Gender & Female & 85 & 40,7 \\
Age & Male & 124 & 59,3 \\
& $18-23$ & 11 & 5,3 \\
& $24-29$ & 39 & 18,7 \\
& $30-35$ & 54 & 25,8 \\
& $36-41$ & 56 & 26,8 \\
& $42-47$ & 25 & 12 \\
Marital status & $48-53$ & 17 & 8,1 \\
& 54 and over & 7 & 3,3 \\
& Single & 66 & 31,6 \\
Education level & Married & 135 & 64,6 \\
& Widowed & 1 & 0,5 \\
& Divorced & 7 & 3,3 \\
& Primary School Graduate & 1 & 0,5 \\
& High School Graduate & 25 & 12 \\
& Bachelor's Degree & 24 & 11,5 \\
& Master's Degree & 131 & 62,7 \\
\hline
\end{tabular}

$40.7 \%$ of the participants were female and $59.3 \%$ were male. $71.3 \%$ of the participants were between the ages of $24-41.64,6 \%$ of the participants were married and $62,7 \%$ were bachelor's degrees. The participants were asked about the "Which of the following affects your psychology more negatively than the other?" question. $\% 52,6$ of the participants $(n=110)$ responded as "Burnout due to the workload on you" and \%47,4 ( $n=99)$ of the participants responded as "You are bored because of the meaningless or low job/task".

\section{Confirmatory Factor Analysis}

The construct validity of the scales was revealed by Confirmatory factor analysis (CFA) (Byrne, 2013). The type of analysis that proves that the latent variable is measured by the observed variable is the Confirmatory Factor Analysis. The CFA model (estimated model) is as follows. (figure 1).

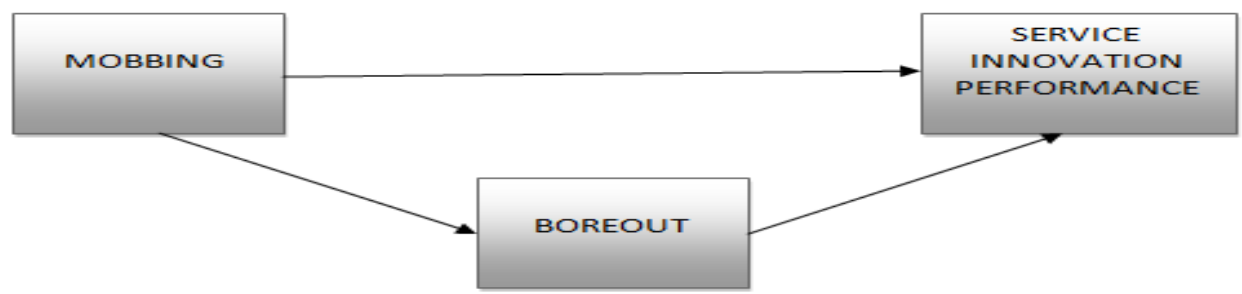

Figure 1. The research model

During the CFA analysis, the model did not show a good fit [ $\chi 2$ (209): 2348,392, p <.01; $\chi 2 /$ df: 5,842; SRMR: .703; RMSEA: .153; NNFI: .513; IFI: .554; CFI: 550; GFI: .508; AGFI: .431]. Initial model fit values are shown in figure 1. Providing good fit values of the model depends on the elimination of associated errors during the CFA. Correlated errors can be eliminated by discarding low-load items from the model or linking similar items (Brown, 2015). However, these procedures should be suitable for the purpose of the study. Due to some of the items in the subscales of the mobbing, boreout and service innovation performance scales are similar to each other, and each of these items has significant effects on measuring the scales, four items discarded from the model. When the fitness indexes failed to achieve the required level there are some suggestions for using cutoffs. If the factor loadings of the items are below 0,6 (Field, 2005) or 0,4 (Stevens, 1992) these items should be 


\section{F. Özsungur 12/1 (2020) 28-42}

discarded from the model until achieving the required level of Fitness Indexes. This procedure is performed by discarding only one item at a time. After deleting each item, the research model should be checked again. Following this procedure, the standardized regression weights (SRW) of CG2 (SRW=,262), CG4 (SRW=,155), ESIB1 (SRW=,395), ESIB2 (SRW=,361) did not meet the criteria and these items were discarded from the model step by step. Then, as Brown (2015) suggested, items with high covariance values were linked to each other and good fit values were obtained.

Data on the good fit coefficients of the model are presented in Table 2. According to these data, it is seen that the model meets the good fit criteria [ $\chi 2$ (209): 400,576, p > .01; $\chi 2$ /df: 1,495; SRMR: ,038; RMSEA: ,049; NNFI: ,951; IFI: ,961; CFI: ,960; GFI: ,876; AGFI: ,837].

Table 2. Model Fit Coefficients

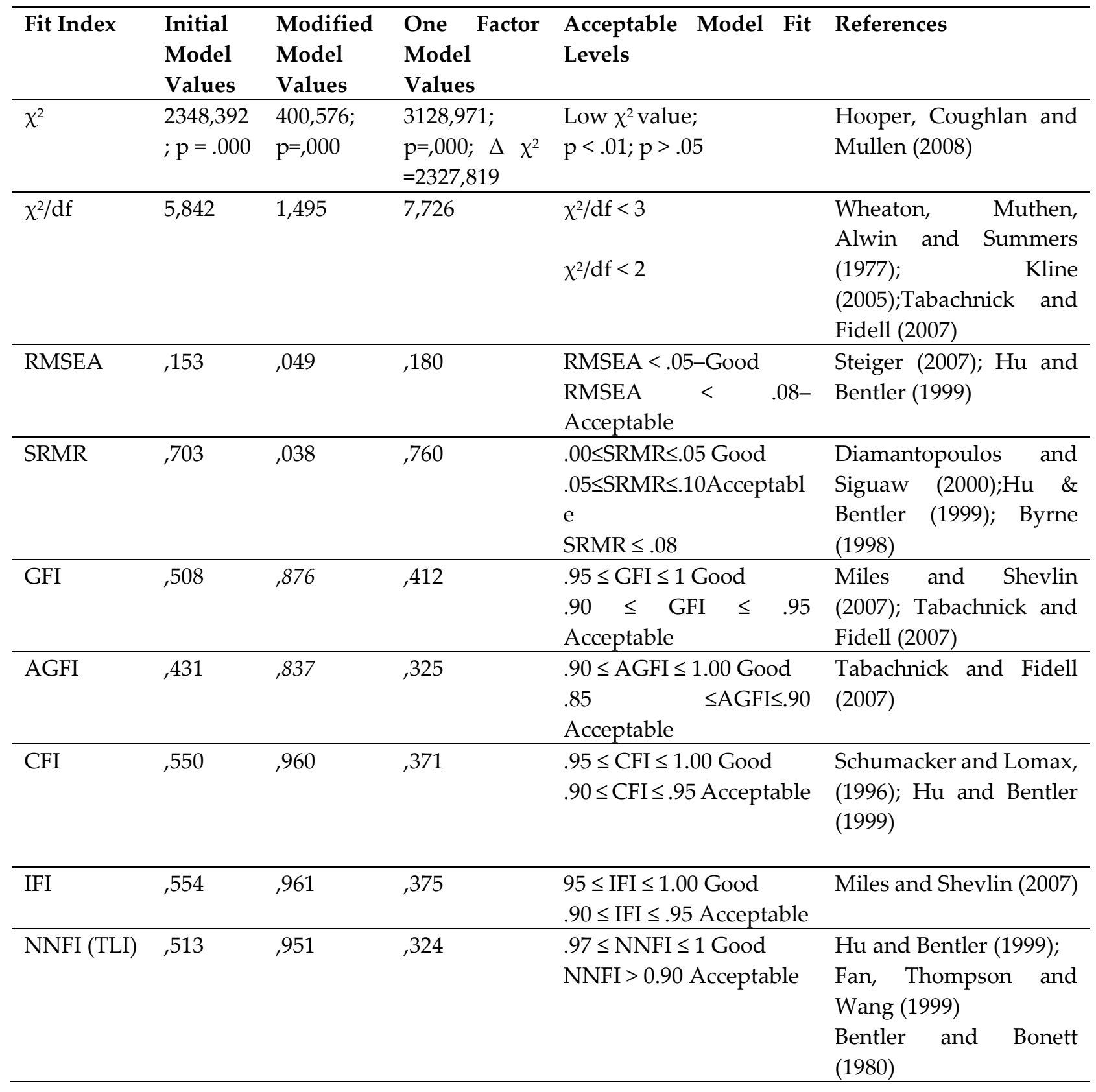

$\chi^{2}$ Discrepancy Chi Square; $\chi^{2} / \mathrm{df}$ (Chi Square/Degrees of Freedom); CFI (Comparative Fit Index); IFI (Incremental Fit Index); RMSEA (Root Mean Square of Error Approximation); NNFI (Non-Normed Fit Index ); SRMR (Standardized Root Mean Square Residual); GFI (Goodness of Fit Index); AGFI (Adjusted Goodness of Fit); TLI (Tucker-Lewis Index)

The latent variables of the scales were tested with confirmatory factor analysis. This structure was compared with a single factor structure. $\chi 2$ values were compared with each other. The significance of the value variation 


\section{F. Özsungur 12/1 (2020) 28-42}

in the data obtained was measured. With this method, the existence of common method bias (CMB) was examined (MacKenzie and Podsakoff, 2012). Comparison results of the single factor model were presented in table 2. According to the data obtained, a significant difference was found between the single-factor structure and the three-factor structure $(\Delta \chi 2=2327,819 ; \mathrm{p}<.01)$. However, considering the criticism that the comparison of the single-factor structure and the existing structure was not a valid method in determining $\mathrm{CMB}$, the threephase CFA marker technique was implemented (Williams, Hartman and Cavazotte, 2010). Thus, whether there was a deviation in the measurement tools used in the research could be revealed more clearly. During the implementation of this method, two factors, common and latent, were added to the structure. The quality of the effects of the method in Phase I was determined by the marker variable as follows: (Baseline-> Method$\mathrm{C}: \Delta \chi 2=8,04, \Delta \mathrm{df}=1, \mathrm{p}<.01$ ). On the other hand, reliability decomposition was measured in phase II (MethodC-> Method-U: $\Delta \chi 2=33.2, \Delta \mathrm{df}=23, \mathrm{p}<.01$ ). Finally, a sensitivity analysis was detected in phase III (Method$\mathrm{U}<-$ Method-R: $\Delta \chi 2=1.6, \Delta \mathrm{df}=4$ ). During the sensitivity analysis, the unstandardized method factor loadings were measured in the range of .01 and .05 $\alpha$ levels. Findings showed that there was no common method bias in the measurement tools used in the study (MacKenzie and Podsakoff, 2012).

When the model fit indices were examined, all other fit indices except GFI and AGFI values were found to be good or acceptable. In SEM analysis, AGFI and GFI values vary according to sample size and are not an absolute indicator of a good fit of the model (Hu and Bentler, 1999; Kline, 2016). In determining good fit values, the recommended indices to calculate the model and to prove a valid structure are IFI and CFI (Hu and Bentler, 1999). The findings obtained according to the measurements prove that the model fits well. In addition, the mediation analysis fit indices were found to be above the values recommended in the literature.

Mobbing scale consists of 5, boreout scale consists of 11, service innovation performance consists of 14 items. The factor loadings of the items of these scales are in the range of, 63 and, 91. Tabachnick and Fidell (2007) stated that when the threshold value of factor loadings changes depending on the sample size and in large samples the factor loading value of, 300 may be sufficient to define an implicit variable. According to the obtained values, the related items can measure the scale without errors. Furthermore, the average variance extracted (AVE) values were determined as service innovation performance (SIP) $=0.447$, mobbing $=0.514$ and boreout $=0.352$. According to the discriminant validity, the square root of the AVE for boreout was less than one the absolute value of the correlations with another factor. According to the convergent validity, the AVE for SIP and boreout were less than 0.50. In compliance with discriminant validity, the AVE for boreout is less than the MSV. According to Hu and Bentler (1999), convergence validity is provided if the average variance extracted (AVE) values are higher than 0.50. According to Kline $(2005 ; 2016)$, if the CR value is over 0,70, AVE value can be less than 0,50 (Fornell and Larcker, 1981; Hair et al., 2016; Nunnally, 1976). In light of these results, it can be said that the observed items have convergent and discriminant validity to measure the research scales.

Table 3. Discriminant and Convergent Validity of the Model

\begin{tabular}{|l|l|l|l|l|l|l|l|l|}
\hline & $\alpha$ & CR & AVE & MSV & MaxR(H) & SIP & MOBBING & BOREOUT \\
\hline SIP & 0,913 & 0,901 & 0,447 & 0,234 & 0,928 & $0,669^{a}$ & & \\
\hline MOBBING & 0,844 & 0,839 & 0,514 & 0,402 & 0,860 & $-0,484^{*}$ & $0,717^{a}$ & \\
\hline BOREOUT & 0,836 & 0,814 & 0,352 & 0,402 & 0,865 & $-0,479^{*}$ & $0,634^{*}$ & $0,594^{a}$ \\
\hline
\end{tabular}

$\alpha=$ Cronbach's alpha; $\operatorname{MaxR}(\mathrm{H})=$ maximum reliability; a Square root of $\mathrm{AVE}$ value; $\mathrm{CR}=$ composite reliability; AVE is significant over the 0.50 level, the acceptable value of $C R$ is 0.7 and above; $A V E=$ average variance extracted; MSV= maximum shared variance;; ${ }^{*}$ Pearson Correlation;.

The AVE values of each latent variable must be less than the square root of AVE value for the discriminant validity of the correlation value found among the factors (Fornell and Larcker, 1981). The square root of AVE values were determined as $\mathrm{SIP}=0,669$, mobbing $=0,717$ and boreout $=0,594$. Since these values were greater than the correlation values between the two factors $(-0,484 ;-0,479 ; 0,634)$, the discriminant validity was also obtained. The composite reliability values of the factors were measured as SIP $=0.901$, mobbing $=0.839$ and boreout $=0.814$. Cronbach's $\alpha$ values with internal consistency coefficients were also calculated and measured 


\section{F. Özsungur 12/1 (2020) 28-42}

as $\mathrm{SIP}=0.913$, mobbing $=0.844$ and boreout $=0.836$. In light of these results, SIP, mobbing, and boreout were found to be valid and reliable.

\section{Mediation Analysis}

Mediation analysis and path analysis were performed in the study using IBM SPSS AMOS software. In this method, the indirect effects are revealed. The fact that the explained variance is over $80 \%$ is a full mediation indicator. The explained variance rate of less than $80 \%$ and more than $20 \%$ reveals evidence for partial mediation. The rate below 20\% indicates that there is no mediation (Hayes, 2013; Howell, 2010).

The model fit coefficients of the model examined to test mediation effects were given in table 4 . The effects of the exogenous variable of mobbing on the endogenous variables of SIP $(t=-3,508, p<.01)$ and boreout $(t=$ $7,910, \mathrm{p}<.01$ ) were found to be significant in this model. Then, in the presence of the boreout variable, indirect effects were analyzed using the Bootstrap method by the IBM SPSS AMOS software (Byrne, 2013). The Bootstrap method provides information about the validity of the results if the data set is large on certain proportions and the same features (Sacchi, 1998). Bootstrap method is recommended because it is a reliable method in the calculation of indirect effects in mediation analyzes (Hair et al., 2016, 2006).

Table 4. Mediation Analysis Results

\begin{tabular}{|l|l|l|l|l|l|l|l|}
\hline Boreout & $\begin{array}{l}\text { Total } \\
\text { Effects }\end{array}$ & $\begin{array}{l}\text { Direct } \\
\text { Effects }\end{array}$ & $\begin{array}{l}\text { Indirect } \\
\text { Effects }\end{array}$ & $\begin{array}{l}\text { Lower } \\
\text { Bounds }\end{array}$ & $\begin{array}{l}\text { Upper } \\
\text { Bounds }\end{array}$ & p & Mediation Effect \\
\hline $\begin{array}{l}\text { Mobbing- } \\
\text { SIP }\end{array}$ &, 001 &, 002 &, 004 &,- 218 &,- 055 &, $002^{* *}$ & Partially (TVE:23,1\%) \\
\hline
\end{tabular}

Notes: The confidence interval values for indirect effects were calculated by bootstrap with $\mathrm{N}=2090$. TVE: Total variance explained; ${ }^{* * *} \mathrm{p}$ is significant at 0.01 (two tailed); ${ }^{*}$ significant at 0.1 (two tailed); ${ }^{* *} \mathrm{p}$ is significant at 0.05 (two tailed) If zero (0) does not match within the confidence interval values, the indirect effect is significant.

According to research results, it is estimated that the predictors of boreout explain $23,1 \%$ of its variance. In other words, the error variance of boreout is approximately $76,9 \%$ of the variance of boreout itself. For this reason, boreout partially mediates the association between mobbing and SIP. The indirect effect of boreout was found to be significant (Mobbing $\rightarrow$ Boreout $\rightarrow$ SIP), the confidence interval was as the lower bounds= , 218 and the upper bounds $=-, 055, \mathrm{p}<.01$, and total variance explained ratio calculated for $23,1 \%$. Under these conditions, the boreout variable partially mediated the association between mobbing and SIP. After these findings, the model tested in the study was as in figure 2. As a result, the effect of mobbing on SIP can be said to be partially directed by the boreout.

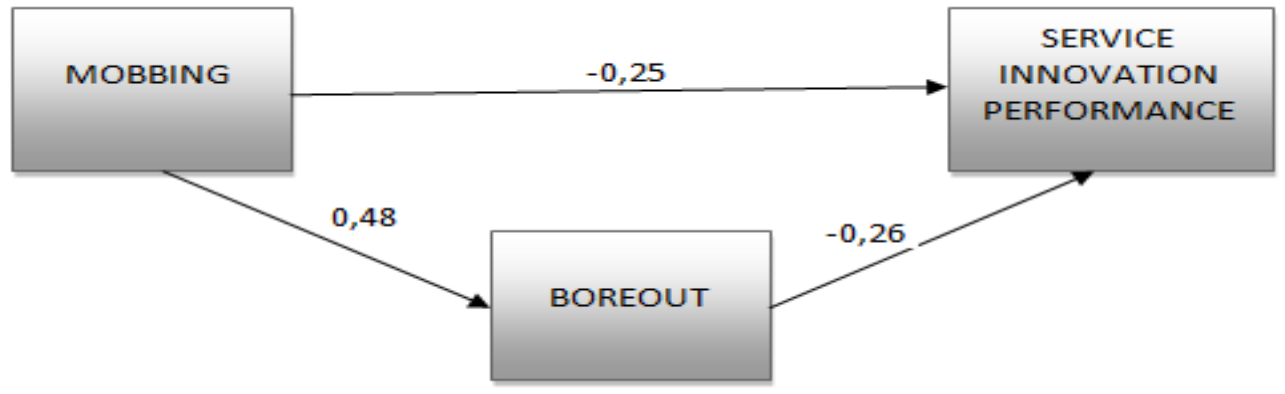

Figure 2. Mediation model with standardized estimates

\section{Results of hypotheses}

According to findings mobbing was negatively associated with SIP (H1: $\beta=-0,249 \mathrm{t}=-3,508 ; \mathrm{p}<0,01)$, mobbing was positively associated with boreout $(\mathrm{H} 2: \beta=0,481 ; t=7,910 ; \mathrm{p}<0,01)$, boreout was negatively associated with SIP (H3: $\beta=-0,261 ; t=-3,681 ; p<0,01$ ). Thus, hypotheses H1, H2, H3 for direct effects were supported. The $t, \beta$ and $p$ values and hypothesis support/reject results of hypotheses were given in Table 5 . As the results of the 


\section{F. Özsungur 12/1 (2020) 28-42}

research indicated that the boreout level increased when mobbing increased, but the SIP decreased. SIP was reduced when the boreout level increased.

Table 5. Research hypotheses test results for direct effects table.

\begin{tabular}{|l|l|l|l|l|}
\hline Alternative Hypotheses & Conclusion & $\mathrm{t}(2090)$ & $\beta$ & $\mathrm{p}$ \\
\hline $\mathrm{MOB} \rightarrow$ Boreout & Supported & 7,910 &, 481 & 0.01 \\
\hline $\mathrm{MOB} \rightarrow$ SIP & Supported & $-3,508$ &,- 249 & 0.01 \\
\hline Boreout $\rightarrow$ SIP & Supported & $-3,681$ &,- 261 & 0.01 \\
\hline
\end{tabular}

$\mathrm{t}$ : Critical ratio; $\beta$, Standard Beta; ${ }^{*} 0.1$ level (2-tailed); ${ }^{* *} \mathrm{p}$ is significant at 0.05 level (2-tailed) ${ }^{* * *} \mathrm{p}$ is significant at 0.01 level (2-tailed).

In the study, the mediating effect of hypothesis testing for indirect effects was tested. The effects of exogenous variable (mobbing) on endogenous variable (SIP) were found to be significant [Mobbing $\rightarrow$ Boreout $\rightarrow$ SIP; $\mathrm{t}(2090)=-, 218 ;-, 055 ; \mathrm{p}<0,01$; total variance explained percent: $23,1 \%]$. These results showed that boreout partially mediated the effect of the Mobbing on SIP. The findings supported the hypothesis of $\mathrm{H} 4$ for indirect effects.

\section{Discussion}

Each scale was divided into different groups in the questionnaire to eliminate the common method variance effect in measurement tools. The scales of the independent variables were arranged to be before the scales of the dependent variables. (Podsakoff and Organ, 1986). The CFA marker technique which was recommended by Williams, Hartman, and Cavazotte (2010) and implemented in this study proved the low effect of the measurement tools on the participants' evaluations.

The effects of mobbing and boreout on the service innovation performance of the organization were examined in this study. It was found that mobbing was negatively associated with SIP (H1), mobbing was positively associated with boreout (H2), boreout was negatively associated with SIP (H3). Previous studies revealed the association between mobbing and personal dignity (Serin, Balkan and Doğan, 2014), health-related outcomes Garthus-Niegel et al., 2015), unfavorable workplace incidents (Mardanov and Cherry, 2018), negative acts (Mardanov and Cherry, 2018; Zapf and Einarsen, 2005; Zapf, Knors and Kulla, 1996) and well-being (Mardanov and Cherry, 2018). These studies demonstrate the negative effects of mobbing on workers (H1, H2). However, no study was found directly related to the hypothesis results.

Another issue that affects the employee negatively is boreout. Boreout is the negative psychological state of the employee concerning a crisis of meaning at work, job boredom, and the crisis of growth. Previous studies showed the negative effect of boreout on employees. Stock (2015) found that the crisis of meaning at work and crisis of growth negatively associated with employee innovative work behavior contrary to job boredom. In a research conducted by the same author in 2016, it was revealed that crisis of meaning at work, job boredom and crisis of growth which were the dimensions of boreout negatively effected customer-oriented behavior (Stock, 2016). According to a study conducted in 2018, it was found a negative inter-individual correlation between engagement and burnout (Moeller et al., 2018).

Service innovation performance is the sum of the employee's positive entrepreneurial behaviors and supporting operations of enterprises aimed at these behaviors. Researches revealed the association between service innovation performance and close cooperation with customers (Santamar1'a, Nieto and Miles, 2012), intentions and behaviors (Schmit and Allscheid, 1995), team culture and knowledge sharing (Hussain, Konar, and Ali, 2016). These studies demonstrate the negative effects of boreout on the employee. The findings of Stock's $(2015,2016)$ studies regarding the relationship between boreout with customer-oriented behavior and employee innovative work behavior were close to the hypothesis of H3. However, no study was found directly related to this hypothesis result. 


\section{F. Özsungur 12/1 (2020) 28-42}

The most important finding of the study was the mediation role of boreout in the association between mobbing and SIP (H4). A study supporting this hypothesis was not found in the literature. Events that negatively affecting employees decrease their productivity and creativity. Findings of the study showed that the employees who are under the effects of harassment, psychological stress, oppressive, insulting, threatening, coworker bullying in the workplace negatively affected the creative and innovative service behaviors and development of new services. Boreout partially mediated this negative effect. This mediation effect revealed the role of boreout on the negative atmosphere with mobbing.

Findings revealed that burnout due to the workload (burnout) and the meaningless or low job/task (boreout) almost affect equally employee's psychology. This comparison was not found in the literature. This finding proves the great impact of boreout on the employee.

\section{Limitations and recommendations for future studies}

Increasing the stress on the employees with the changing business world and developing technology has been inspired by this study. Investigating the effects of mobbing on employees in the business world, especially in developing countries, would provide important predictions to global policymakers. In the literature, there were few studies on the effects of negative states such as mobbing and boreout on the employees. However, there were some limitations to the study.

The fact that the study limited with employees in the manufacturing sector enterprises in the Adana Turkey sample affected the generalizability of the results (Converse and Presser, 1986). Boreout and mobbing scales containing negative items can create inconsistency in terms of the responses. Unlike other subscales, the positive items of the crisis of growth subscale which had low standardized regression weights of boreout were discarded from the model. These items cause participants to be more sensitive to positive items while focusing on negative items of boreout. For this reason, the crisis of growth items of boreout scale creates a significant limitation in terms of the findings of the study, which makes a difference in the perception of individuals and causes sensitivity. For future studies, it is recommended that the scale should be reexamined, and using negative items instead of reversed positive items in the same way for other subscales of boreout.

When the results of the study are evaluated together, the new knowledge contributed to the literature is as follows: boreout mediates the negative effect of lay mobbing behaviors on service innovation performance. This new knowledge shows that the negative effects of mobbing such as harassment, psychological stress, oppressive, insulting, threatening, coworker bullying the employees and the organization have negative effects on innovation and creativity in offering services via the effects of boreout such as crisis of meaning at work, job boredom, and crisis of growth.

It is recommended that policymakers in organizations, especially in developing countries, should develop strategic human resource management practices that can minimize the factors negatively affecting employees such as boreout and mobbing. To eliminate the negative effects of boreout on innovative behaviors in organizations, recruitment and placement should be carried out by taking into account the individual characteristics. Therefore, it should be emphasized the stress factors on the individual for efficiency and performance in organizations' human resources management and the tasks assigned to employees being directly proportional to the competencies of the individual. An individual who is not satisfied with his job, working under constant stress and regarding his job as meaningless may not be able to create synergy for the organization. Achieving a sustainable competitive advantage is possible with the importance given to the human factor that provides innovation in the service and affects the performance of the organization.

It is thought that this study will provide a prediction for future researches in the literature. It is recommended to investigate mediation or direct effects of different variables (e.g. psychological capital, ethical leadership, transformational leadership, psychological empowerment, career commitment, authentic leadership, organizational justice, affective participation, job satisfaction, organizational voice/silence behavior) on the association between boreout mobbing and service innovation performance. Furthermore, considering the association between boreout and mobbing, these scales can be developed. 


\section{F. Özsungur 12/1 (2020) 28-42}

\section{References}

Agervold, M. \& Mikkelsen, E. (2004). Relationships between bullying, psychosocial work environment and individual stress reactions. Work \& Stress, 18, 4, 336-51.

Bagozzi, R. P. (1992). The self-regulation of attitudes, intentions, and behavior. Social Psychology Quarterly, 55(2), 178-204.

Bakker, A. B., M. van Veldhoven, \& D. Xanthopoulou. (2010). Beyond the demand-control model. Thriving on high job demands and resources. Journal of Personnel Psychology. 9 (1), 3-16.

Barcet, A. (2010). Innovation in services: a new paradigm and innovation model. In F. Gallouj \& F. Djellal (Eds.), The Handbook of Innovation and Services: A Multidisciplinary Perspective (pp. 49-67). Cheltenham: Edward Elgar.

Bentler P M \& Bonett D G. (1980). Significance tests and goodness of lit in the analysis of covariance structures. Psychol. Bull., 88, 588-606.

Bentler, P.M. (1990). Comparative Fit Indexes in Structural Models. Psychological Bulletin, 107 (2), 238-246.

Berthon, P. \& John, J. (2006). From entities to interfaces: delineating value in customer-firm interactions. In R.F. Lusch \& S. L. Vargo (Eds), The Service-Dominant Logic of Marketing - Dialog, Debate, and Directions (pp. 196-207). Armonk, NY: M.E. Sharpe.

Blau, P. (1964). Exchange and power in social life. New York, NY: Wiley \& Sons.

Bollen, K. A. (1989). A new incremental filt index for general structural equation models. Sociological Methods and Research, 17, 303-316.

Brown, T. A. (2015). Confirmatory factor analysis for applied research. Guilford Publications.

Byrne, B.M. (1998). Structural Equation Modeling with LISREL, PRELIS and SIMPLIS: Basic Concepts, Applications and Programming. Mahwah, New Jersey: Lawrence Erlbaum Associates.

Byrne, B. M. (2013). Structural equation modeling with amos: basic concepts, applications, and programming (Second Edition). Taylor \& Francis.

Carlborg, P., Kindström, D.\& Kowalkowski, C. (2014). The evolution of service innovation research: a critical review and synthesis. The Service Industries Journal, 34 (5), 373-398.

Chen, W.J. (2011). Innovation in hotel services: Culture and personality. International Journal of Hospitality Management, 30(1), 64-72.

Converse, J. M., \& Presser, S. (1986), Survey questions: Handcrafting the standardized questionnaire,

Newbury Park, CA: Sage Publications.

Dess, G.G. \& Picken, J.C. (2000). Changing roles: leadership in the 21st century. Organizational Dynamics, 28 (3), 18-34.

Diamantopoulos, A. \& Siguaw, J.A. (2000). Introducing LISREL. London: Sage Publications.

Dutton, J. E., L. M. Roberts, \& J. Bednar. (2010). Pathways for positive identity construction at work: Four types of positive identity and the building of social resources. Academy of Management Review, 35 (2), 265-93.

Erwin, E., (2002). The Freud Encyclopedia Theory, Therapy and Culture. England: Routledge.

Fan, X., Thompson, B. \& Wang, L. (1999). Effects of Sample Size, Estimation Methods, and Model Specification on Structural Equation Modeling Fit Indexes. Structural Equation Modeling, 6 (1), 56-83.

Field, A.(2005). Discovering Statistics Using SPSS, 2nd edn, London: SAGE.

Fisher, C. D. (1998). Effects of external and internal interruptions on boredom at work: Two studies. Journal of Organizational Behavior, 19 (5), 503-22.

Fornell, C. \& Larcker, D. F. (1981). Evaluating structural equation models with unobservable variables and measurement error. Journal of marketing research, 39-50. 


\section{F. Özsungur 12/1 (2020) 28-42}

Garg, S. \& Dhar, R. L. (2017). Employee service innovative behavior: The roles of leader-member exchange (LMX), work engagement, and job autonomy. International Journal of Manpower, 38 (2), 242-258.

Garthus-Niegel, S., Nübling, M., Letzel, S., Hegewald, J., Wagner, M., Wild, P. S., Blettner, M., Zwiener, I., Latza, U., Jankowiak, S., Liebers, F., ... Seidler, A. (2015). Development of a mobbing short scale in the Gutenberg Health Study. International archives of occupational and environmental health, 89(1), 137-46.

Gefen, D., Straub, D. \& Boudreau, M.-C. (2000). Structural Equation Modeling and Regression: Guidelines for Research Practice. Communications of the Association for Information Systems, 4(1), 2-77.

Hair, J. F., Black, W. C., Babin, B. J., Anderson, R. E., \& Tatham, R. L. (2006), Multivariate data analysis (6th ed.), Upper Saddle River, NJ: Prentice-Hall.

Hair Jr, J. F., Hult, G. T. M., Ringle, C. \& Sarstedt, M. (2016). A primer on partial least squares structural equation modeling (PLS-SEM). Sage Publications.

Hastie, R. \& Pennington, N., (1995), Cognitive Approaches To Judgment And Decision Making, In Busemeyer, J., Medin, D.L. and Hastie, R. (Ed.), Decision Making from a Cognitive Perspective, Academic Press, San Diego, CA: 1-31.

Hayes, A. F. (2013). Mediation, moderation, and conditional process analysis. Introduction to Mediation, Moderation, and Conditional Process Analysis: A Regression-Based Approach. New York: Guilford Publications, 1-20.

Hooper, D., Coughlan, J. \& Mullen, M. (2008). Structural equation modelling: guidelines for determining model fit. Electronic Journal of Business Research Methods, 6(1), 53-60.

Howell, D. C. (2010). Statistical Methods for Psychology. 7. Ed. Belmont: Wadsworth, Cengage Learning.

Hu, L. \& Bentler, P.M. (1999). Cutoff Criteria for Fit Indexes in Covariance Structure Analysis: Conventional Criteria Versus New Alternatives. Structural Equation Modeling: A Multidisciplinary Journal, 6(1), 1-55.

Hu, M.L.M., Horng, J.S. \& Sun, Y.H.C. (2009). Hospitality teams: knowledge sharing and service innovation performance. Tourism Management, 30 (1), 41-50.

Hussain, K., Konar, R. \& Ali, F. (2016). Measuring Service Innovation Performance through Team Culture and Knowledge Sharing Behaviour in Hotel Services: A PLS Approach. Procedia - Social and Behavioral Sciences, 224, 35-43.

Janssen, O. (2000). Job demands, perceptions of effort-reward fairness and innovative work behavior. Journal of Occupational and Organizational Psychology, 73 (3), 287-302.

Kandampully, J. \& Duddy, R. (1999). Competitive advantage through anticipation, innovation and relationships. Management Decision, 37 (1), 78-103.

Kindström, D., Kowalkowski, C. \& Sandberg, E. (2013). Enabling service innovation: A dynamic capabilities approach. Journal of Business Research, 66 (8), 1063-1073.

Kline, R.B. (2005). Principles and Practice of Structural Equation Modeling (2nd Edition ed.). New York: The Guilford Press.

Kline R. B. (2016). Principles and Practices of Structural Equation Modeling (4th Edn). New York, NY: The Guilford Press.

Laplanche, J. \& Pontalis, J. B. (2006). The Language of Psychoanalysis. H. Karnac Books.

Leymann, H. (1996). The content and development of mobbing at work. European Journal of Work and Organizational Psychology, 5, 165-184.

MacCallum, R.C., Browne, M.W. \& Sugawara, H., M. (1996). Power Analysis and Determination of Sample Size for Covariance Structure Modeling. Psychological Methods, 1 (2), 130-49.

MacCallum, R. C. \& Hong, S (1997). Power Analysis in Covariance Structure Modeling Using GFI and AGFI. Multivariate Behav Res., 32(2), 193-210. 


\section{F. Özsungur 12/1 (2020) 28-42}

Mardanov,I., \& Cherry, J. (2018). Linkages among workplace negative behavioral incidents. Evidence-based HRM: a Global Forum for Empirical Scholarship, 6(2), 221-240.

Maruyama, G. M. (1998). Basics of structural equation modeling. Thousand Oaks, CA, US: SagePublications, Inc.

Matear, S., Gray, B. J., \& Garrett, T. (2004). Market orientation, brand investment new service development, market position and performance for service organizations. International Journal of Service Industry Management, 15(3/4), 284-301.

MacKenzie, S.B., \& Podsakoff, P.M. (2012). Common method bias in marketing: Causes,

mechanisms, and procedural remedies. Journal of Retailing, 88, 4, 542-555.

Miles, J. \& Shevlin, M. (2007). A time and a place for incremental fit indices. Personality and Individual Differences, 42(5), 869-874.

Moeller, J., Ivcevic, Z., White, AE., Menges, J.I., \& Brackett, MA. (2018). Highly engaged but burned out: intra-individual profiles in the US workforce. Career Development International, 23 (1), 86-105.

Nunnally, J. C. (1976). Psychometric theory (2nd ed). New York: McGraw-Hill.

Özdamar, K. (2003). Modern Bilimsel Araştırma Yöntemleri. Eskişehir: Kaan Kitabevi

Podsakoff, P. M., \& Organ, D. W. (1986), “Self-reports in organizational research: Problems

and prospects", Journal of Management, Vol. 12 No. 4, pp.531-544.

Sacchi, M.D. (1998). A bootstrap procedure for high-resolution velocity analysis. Geophysics, 63(5), 1716-1725.

Santamarı'a, L., Nieto, M.J. \& Miles, I. (2012). Service innovation in manufacturing firms: evidence from Spain. Technovation, 32(2), 144-155.

Schmit, M. J. \& Allscheid, S. P. (1995). Employee attitudes and customer satisfaction: Making theoretical and empirical connections. Personnel Psychology, 48(3), 521-536.

Schnell, T. (2010). Existential indifference: Another quality of meaning in life. Journal of Humanistic Psychology, $50(3), 351-73$.

Schumacker, R.E. \& Lomax, R.G. (1996). A Beginner's Guide to Structural Equation Modeling. Mahwah. New Jersey: Lawrence Erlbaum Associates, Publishers.

Scott, S. G., \& Bruce, R. A. (1994). Determinants of innovative behavior: a path model of individual innovation in the workplace. Academy of Management Journal, 37(3), 580-607.

Serin, AE., Balkan, MO., \& Doğan, H. (2014). The Perception And Causes Of Mobbing: Turkey Example. Journal of Business, Economics \& Finance, 3(1),5-17.

Sharma, S., Mukherjee, S., Kumar, A., \& Dillon, W.R. (2005). A simulation study to investigate the use of cutoff values for assessing model fit in covariance structure models. Journal of Business Research, 58 (1), 935943.

Steffgen, G., Sischka, P., Schmidt, A. F., Kohl, D., \& Happ, C. (2016). The Luxembourg Workplace Mobbing Scale: Psychometric Properties of a Short Instrument in Three Different Languages. European Journal of Psychological Assessment.

Steiger, J.H. (2007). Understanding the limitations of global fit assessment in structural equation modeling. Personality and Individual Differences, 42(5), 893-898.

Stevens, J.P. (1992). Applied Multivariate Statistics for the Social Sciences (2 nd edition). Hillsdale, NJ: Erlbaum.

Stock, RM. (2016). Understanding the relationship between frontline employee boreout and customer orientation. Journal of Business Research, 69, 4259-4268.

Stock, R. M., \& W. D. Hoyer. (2005). An attitude-behavior model of salespeople's customer orientation. Journal of the Academy of Marketing Science, 33 (4), 536-52. 


\section{F. Özsungur 12/1 (2020) 28-42}

Stock, R. M. (2015). Is boreout a threat to frontline employees' innovative work behavior? Journal of Product Innovation Management, 32(4), 574-592. DOI: 10.1111/jpim.12239.

Tabachnick, B.G. \& Fidell, L.S. (2007). Using Multivariate Statistics (5 ${ }^{\text {th }}$ edition). New York: Allyn and Bacon.

Tanaka, J. S. (1993). Multifaceted conceptions of fit in structural equation models. In J. A. Bollen \&J. S. Long (Eds), Testing structural equation models (pp. 10-39). Newbury Park, CA: Sage.

Wheaton, B., Muthen, B., Alwin, D. F. \& Summers, G. F. (1977). Assessing Reliability and Stability in Panel Models. In David R. Heise (Ed.). Sociological Methodology Jossey-Bass (84-136). San Francisco.

Williams, L. J., Hartman, N. \& Cavazotte, F. (2010), “Method Variance and Marker

Variables: A Review and Comprehensive CFA Marker Technique", Organizational Research

Methods, 13 (3), 477-514.

Woodruff, R.B. (1997). Customer value: the next source for competitive advantage. Journal of the Academy of Marketing Science, 25 (2), 139-153.

Vega, G. \& Comer, D. (2005). Sticks and stones may break your bones but words can break your spirit: bullying in the workplace. Journal of Business Ethics, 58, 1-3, 101-109.

Zapf, D., Knors, C. \& Kulla, M. (1996). On the relationship between mobbing factors and job content, social work environment, and health outcomes. European Journal of Work and Organizational Psychology. 5(2), 215-237.

Zapf, D. \& Einarsen, S. (2001). Bullying in the workplace: Recent trends in research and practice:an introduction. European Journal of Work and Organizational Psychology, 10(4), 369-373.

Zapf, D. \& Einarsen, S. (2005). Mobbing at work: escalated conflicts in organizations. in Fox, S. \& Spector, P.E. (Eds), Counterproductive Work Behavior, American Psychological Association, Washington, DC, 237270 . 